\title{
RAPD-PCR as a molecular discriminative technique for human pathogenic bacteria- A Review
}

\author{
Partha Pal \\ Department of Zoology, Scottish Church College, 1 \& 3 Urquhart Square, Kolkata - 700006, India \\ E-mail address: parthapal_iicb@yahoo.co.in
}

Keywords: RAPD-PCR; Discriminating technique; Pathogenic bacteria; Genomic variability

\begin{abstract}
The application of random amplified polymorphic DNA- polymerase chain reaction (RAPD-PCR) was found to be a simple, cheap and rapid tool to discriminate human pathogenic bacterial isolates especially at intraspecific level. This molecular biological technique relies on the use of random oligonucleotide primers that arbitrarily amplifies specific regions of the genome which gives rise to a unique genomic fingerprint of the strains under investigations. With continued development of novel molecular-based technologies for rapid, high-throughput detection of food borne pathogenic bacteria, the future of conventional microbiological methods such as viable cell enumeration, selective isolation of bacteria on commercial media, and immunoassays seems tenuous. Approaches that enhance recovery of sub lethally injured bacteria, differentiation among species, differentiation among bacteria of interest using biochemical profiling, enumeration using impedance technology, techniques to confirm the presence of target pathogens using immunological methods, and bioluminescence applications for hygiene monitoring are of utmost need in identifying and combating the human pathogenic isolates. The aim of this study is to estimate the efficiency of RAPD-PCR technique in assessing the genetic diversity of diseases causing bacterial isolates. The use of RAPD-PCR in evaluating the genomic variability among the pathogenic strains belonging to different genus are also been discussed in the present report.
\end{abstract}

\section{INTRODUCTION}

Pathogens are a major pollutant of pharmaceutical according to many reports. Various sources contribute pathogens to contaminated pharmaceutical, including fecal pollution from humans, wildlife, and livestock. The presence of any fecal bacteria in pharmaceutical is considered as a health hazard. Knowing the source(s) of bacteria in pharmaceutical is of great value in the remediation and prevention of further bacterial contamination. Phenotypic methods and molecularbased techniques were used to determine the source of faecal pathogen contamination in environmental samples. Phenotypic methods play an important role in identification of genus level. Serotyping, based on the Kauffmann-White scheme, remains the standard for classification of Salmonella isolates in outbreak investigations but now has been supplemented by a range of molecular genotyping methods $[1,2]$. In recent years, molecular-based techniques, such as PulsedField Gel Electrophoresis (PFGE), Restriction Fragment Length Polymorphism (RFLP), Random Amplified Polymorphic DNA (RAPD), Automatic Ribo-typing, rep-PCR, Multi-Locus Sequence Typing (MLST) have been shown to be useful methods for discrimination among isolates of pathogens [3, 4]. Molecular-typing methods including rep-PCR, Multi-Locus Sequence Typing (MLST) have been shown to be useful methods for discrimination among isolates of pathogens [3, 4].

Recent advances in molecular techniques have generated several typing methods based on PCR for genetic assessment of genetic relatedness of bacterial or fungal strains. One of them, RAPD-PCR (random amplified polymorphic DNA-polymerase chain reaction) analysis is a useful discriminatory method of Candida spp. in clinical practice [5, 6, 7, 8, 9]. Thus the use of RAPD$\mathrm{PCR}$ in pathogenic strain discrimination is a cost effective, quick and reliable technology in the current era of molecular taxonomy. 


\section{THE RAPD-PCR}

The RAPD-PCR technique is based on the use of an arbitrary oligonucleotide primer as for example in a study conducted on pathogenic strains belonging to genus Candida, the causative agents for vaginal candidiasis, the random primer PA03 (5'-AGTCAGCCAC-3'; custom-made by Operon Technologies) was used for DNA fingerprinting, using the conditions described by $\mathrm{Xu}$ et al. (1999) [10] with slight modifications. DNA amplifications were performed in $25 \mu 1$ volumes that contained 10-40 ng DNA template, $2 \cdot 5 \mu 1103$ PCR buffer, $1.5 \mu 125 \mathrm{mM} \mathrm{MgCl}_{2}, 20$ pmol PA03 primer, $2.5 \mu 10.5 \mathrm{mM}$ dNTP mixture and 0.5 U SuperTherm DNA polymerase (Bertec Enterprise). For the negative control, sterile distilled water was used as substitute for the DNA template. RAPDPCR was carried out by using a thermal cycler (Biometra) with an initial denaturation step of $97^{\circ} \mathrm{C}$ for $3 \mathrm{~min}$, followed by 45 cycles of $60 \mathrm{~s}$ at $93{ }^{\circ} \mathrm{C}, 60 \mathrm{~s}$ at $36^{\circ} \mathrm{C}$ and $120 \mathrm{~s}$ at $72{ }^{\circ} \mathrm{C}$, and a final extension cycle of $5 \mathrm{~min}$ at $72{ }^{\circ} \mathrm{C}$. Amplicons were separated by electrophoresis in $1.5 \%$ agarose gel with added ethidium bromide (final concentration of $0.5 \mu \mathrm{g} \mathrm{ml}^{-1}$ ) in $13 \mathrm{TBE}$ buffer for $4 \mathrm{~h}$ at 2 $\mathrm{V} \mathrm{cm}{ }^{-1}$, using the Maxicell Primo horizontal gel electrophoresis system (EC Apparatus). Bands were visualized by using a UV-light transilluminator and pictures were captured digitally with the Gene Genius BioImaging system (Syngene) [11].

\section{APPLICATIONS OF RAPD-PCR IN DETECTION OF PATHOGENIC ISOLATES}

Using random primers of approximately 10 bases, amplicons throughout the genome are targeted and amplified. Amplified products are subsequently separated on an agarose gel and stained with ethidium bromide. The genetic variation analysis based on RAPD allows proper genetic diversity due to its capacity to generate random markers from the entire genome.

Diaz-Guerra TM et al. have used RAPD with three primers (R-108, R-151 and AP12 h) for typing $11 \mathrm{~A}$. flavus isolates and they have found a satisfactory discriminatory power [12] and Hara Kudo et al. have used RAPD to analysis the molecular typing of $V$. parahaemolyticus. And the results indicated that most $\mathrm{O} 3: \mathrm{K} 6 \mathrm{tdh}$ positive strains belonged to the pandemic 03:K6 clone and suggested that serovariation took place in the Japanese environment [13].

In another case, eighteen samples of the O3:K6 and O3:KUT serotypes of $V$. parahaemolyticus were analyzed by multiplex polymerase chain reaction (m-PCR) for detection of the $t l, t d h$ and $t r h$ genes, by RAPD using two primers, and by amplification of the rDNA $16 \mathrm{~S}-23 \mathrm{~S}$ region. RAPD produced two amplification patterns allowing grouping two $t d h$-Kanagawa-negatives isolates [14].

Cetinkaya indicated that RAPD analysis revealed that this mini-MRSA outbreak was caused by contamination of surgical dressing container with MRSA and nasal MRSA carriage in ward staff. And RAPD seems to be a valuable typing method for analysis of nosocomial MRSA outbreaks because of its simplicity and rapidity [15].

RAPD-PCR technology has also been applied to strain discrimination within several species of Candida [16, 17, 18, 19]. Potentially RAPD involves PCR amplification of target genomic DNA sequences with one or more short oligonucleotide primers, followed by separation of the amplimers by agarose gel electrophoresis of Candida isolates. The primer sequence is selected at random and the most suitable primers for a particular species have to be determined empirically. In a number of recent studies, distinctive PCR profiles consisting of multiple amplified fragments were obtained by RAPD with isolates of C. albicans, C. tropicalis, C. glabrata, C. lusitaniae and C. dubliniensis [16, 18]. Furthermore, in one recent study a physiologically homogeneous collection of $C$. parapsilosis isolates was differentiated into three distinct groups by RAPD analysis [18]. In several cases, RAPD profiles of separate isolates of the same species demonstrated intra-species DNA amplimer size polymorphisms.

However, these were more similar to the patterns obtained with other isolates of the same species than RAPD profiles derived from a different species. RAPD has many advantages over other molecular procedures for typing isolates of Candida, including simplicity, speed and large sample volume throughput. However, the reproducibility of RAPD depends on a number of factors, 
each of which must be controlled carefully if accurate and consistent results are to be obtained [20, $21,22]$. Furthermore, although nucleotide sequence information on the organisms being examined is not required, RAPD primers that yield informative profiles with isolates of one Candida spp. may not do so with another. RAPD primer( $s$ ) that yield informative fingerprint profiles with all the Candida spp. isolated regularly from clinical specimens have yet to be described [23].

In another study conducted on Shigella isolates RAPD was performed with primers A4 (5'TGCCCGGACG-3') and A5 (5'-GCCGGGCCT-3') [24] (Bioprobe Systems, Montreuil sous bois, France). Strains were considered non-identical if their RAPD patterns differed by at least two bands. Out of the six RAPD profiles identified, three in Shigella dysenteriae (A, B, C), two in Shigella flexneri (D, E), and one in Shigella boydii 20 (F) were recorded. Two Shigella dysenteriae strains belonging to the B profile did not contain any integrons. All Shigella dysenteriae and the majority of Shigella flexneri strains (11/12) harbouring integrons showed a unique RAPD profile but had a different integron carriage except Shigella boydii 20 strains which showed a unique profile with the same integron content. The data based on the RAPD-PCR technique revealed a clonal spread of integrons among different serotypes of the human enteric pathogenic Shigella strains and a transfer of integrons between different serotypes [25].

\section{DISCUSSION}

All bacterial molecular typing methods currently in use in research are ultimately useful. The challenge is to find out what methods are useful for specific purposes. In this report, the application and progress of molecular typing method based on RAPD-PCR of pathogenic human bacterial strains were described and evaluated. Furthermore, as has been seen in work by other researchers [26], the comparison of a number of methods has allowed the evaluation of the relative strengths and weaknesses of each method in grouping isolates within the bacteria in pharmaceutical. RAPD which is a PCR-based method, has a potential discriminative ability and can therefore be used as a rapid method for molecular epidemiological typing of pathogens. REP-PCR is inferior to RAPDPCR owing to the facts that it was less reproducible and yielded a relatively small number of products and ERIC-PCR was less reproducible and yielded a relatively smaller number of fingerprints compared to RAPD, while the major problem in RAPD typing is a lack of reproducibility of patterns including variation of number, size, and intensity of bands [27] and the interlaboratory reproducibility [28].

\section{CONCLUSION}

With the current trend of emergence of novel bacterial strains having infective potentiality the need for a rapid, cost effective, reliable and reproducible molecular technology is of utmost need in the present scenario. The RAPD-PCR has proved to be a promising and useful molecular method for typing a wide variety of pathogenic bacterial strains that are posing threat to the survivability of mankind. 


\section{References}

[1] N. Botteldoorn, L. Herman, N. Rijpens, et al.: Phenotypic and Molecular Typing of Salmonella Strains Reveal Different Contamination Source in Two Commercial Pig Slaughterhouses. Applied and Environmental Microbiology 70 (2004) 5305-5314.

[2] R. M.Weigel, B. Z. Qiaoa, B. Teferedegneb, D. K. Suh, D. A. Barber, et al.: Comparison of Pulsed Field Gel Electrophoresis and Repetitive Sequence Polymerase Chain Reaction as Genotyping Methods for Detection of Genetic Diversity and Inferring Transmission of Salmonella. Veterinary Microbiology 100 (2004) 205-217.

[3] H. Y. Tsen and J. S. Lin: Analysis of Salmonella Enteritidis Strains Isolated from FoodPoisoning Cases in Taiwan by Pulsed Field Gel Electrophoresis, Plasmid Profile and Phage Typing. Journal of Applied Microbiology 91 (2001) 72-79.

[4] J. Garaizar, N. López-Molina, I. Laconcha, D. L. Baggesen, A. Rementeria, A. Vivanco, et al.: Suitability of PCR Fingerprinting, Infrequent-Restriction Site PCR, and Pulsed-Field Gel Electrophoresis, Combined with Computerized Gel Analysis, in Library Typing of Salmonella Enterica Serovar Enteriditis. Applied and Environmental Microbiology 66 (2000) 5273-5281.

[5] B. Saran, Z. C. Karahan, H. Ağirbaşli, A. Tekeli, A. M. Aksoy: Comparison of different primers used for the genotyping of Candida albicans clinical isolates by randomly amplified polymorphic DNA method. Mikrobiyol Bul 42 (2008) 645-654.

[6] B. Krawczyk, J. Leibner-Ciszak, A. Mielech, M. Nowak, J. Kur: PCR melting profile (PCR MP) - a new tool for differentiation of Candida albicans strains. BMC Infect. Dis .9 (2009) $177-189$.

[7] K. L. Bacelo, K. R. da Costa, J. C. Ferreira, R. C. Candido: Biotype stability of Candida albicans isolates after culture storage determined by randomly amplified polymorphic DNA and phenotypical methods. Mycoses 53 (2010) 468-474.

[8] B. Gültekin, M. Eyigör, Y. Tiryaki, S. Kırdar, N. Aydın: Investigation of antifungal susceptibilities and some virulence factors of Candida strains isolated from blood cultures and genotyping by RAPD-PCR. Mikrobiyol Bul 45 (2011) 306-317.

[9] Y. H. Samaranayake, L. P. Samaranayake, R. S. Dassanayake, J. Y. Yau, W. K. Tsang, B. P. Cheung, Y. Shiren, S. Y. Issa, E. F. Badran, K. F. Akl, A. A Shebabi: Epidemiological characteristics of Candida species colonizing oral and rectal sites of Jordanian infants. BMC Pediatr. 11(2011) 1-6.

[10] J. Xu, C. M. Boyd, E. Livingston, W. Meyer, J. F. Madden, T. G. Mitchell: Species and genotypic diversities and similarities of pathogenic yeasts colonizing women. J. Clin. Microbiol. 37 (1999) 3835-3843.

[11] P. P. Chong, Y. L. Lee, B. C. Tan, K. P. Ng: Genetic relatedness of Candida strains isolated from women with vaginal candidiasis in Malaysia. Journal of Medical Microbiology 52 (2003) 657-666.

[12] T. M. Diaz-Guerra, E. Mellado, M. Cuenca-Estrella, L. Gaztelurrutia, J. I. Navarro, J. L. Tudela: Genetic Similarity among one Aspergillus flavus Strain Isolated from a Patient Who Underwent Heart Surgery and Two Environmental Strains Obtained from the Operating Room. Journal of Clinical Microbiology 38 (2000) 2419-2422.

[13] Y. Hara Kudo, K. Sugiyama, M. Nishibuchi, et al.: Prevalence of Pandemic Thermostable Direct Hemolysin Producing Vibrio parahaemolyticus O3:K6 in Seafood and the Coastal Environment in Japan. Applied and Environmental Microbiology 69 (2003) 3883-3891.

[14] N. C. Leal, S. C. da Silva, V. O. Cavalcanti, et al.: Vibrio parahaemolyticus Serovar O3:K6 Gastroenteritis in Northeast Brazil. Journal of Applied Microbiology 105 (2008) 691-697. 
[15] Y. Cetinkaya, S. Kocagoz, M. Hayran, et al.: Analysis of Minioutbreak of Methicillin-Resistant Staphylococcus aureus in a Surgical Ward by Using Arbitrarily Primed Polymerase Chain Reaction. Journal of Chemotherapy 12 (2000)138-144.

[16] D. J. Sullivan, T. J. Westerneng, K. A. Haynes, D. E. Bennett, D. C. Coleman: Candida dubliniensis sp. nov.: phenotypic and molecular characterization of a novel species associated with oral candidosis in HIV-infected individuals. Microbiology 141 (1995) 1507-1521.

[17] D. Sullivan, D. Bennett, M. Henman, et al.: Oligonucleotide fingerprinting of isolates of Candida species other than $C$. albicans and of atypical Candida species from human immunodeficiency virus-positive and AIDS patients. J. Clin. Micmbiol.31 (1993) 2124-2133.

[18] P. F. Lehmann, D. Lin, B. A. Lasker: Genotypic identification and characterization of species and strains within the genus Candida by using random amplified polymorphic DNA. J. Clin. Micmbiol. 30 (1992) 3249-3254.

[19] A. Bostock, M. N. Khattak, R. Matthews, J. Burnie: Comparison of PCR fingerprinting, by random amplification of polymorphic DNA, with other molecular typing methods for Candida albicans. J. Gen. Micmbiol.139 (1993) 2179-2184.

[20] H. L. C. Coutinho, H. E. Handley BAY Kay, L. Stevenson, J. E. Beringer: The effect of colony age on PCR fingerprinting. Lett. Appl. Micmbiol. 17 (1993) 282-284.

[21] G. Venugopal, S. Mohapatra, D. Salo, S. Mohapatra: Multiple mismatch annealing: basis for random amplified polymorphic DNA fingerprinting. Biochem Biophys. Res. Commun. 197 (1993) 1382-1387.

[22] B. D. Cobb, J. M. Clarkson: A simple procedure for optimising the polymerase chain reaction (PCR) using modified Taguchi methods. Nucleic Acids Res. 22 (1994) 3801-3805.

[23] D. J. Sullivan, M. C. Henman, G. P. Moran, L. C. O'NEILL, D. E. Bennett, D. B. Shanley, D. C. Coleman: Molecular genetic approaches to identification, epidemiology and taxonomy of non-albicans Candida species. J. Med. Microbiol. 44 (1996) 399-408.

[24] M. C. Ploy, F. Denis, P. Courvalin, T. Lambert: Molecular characterization of integrons in Acinetobacter baumanii: Description of an hybrid class 2 integron. Antimicrob. Agents Chemother. 44 (2000) 2684-88.

[25] A. Gassama-Sow, A. Aïdara-Kane, O. Barraud, M. Gatet, F. Denis, Marie-Cécile Ploy: High prevalence of trimethoprim-resistance cassettes in class 1 and 2 integrons in Senegalese Shigella spp isolates. J. Infect. Dev. Ctries. 4(4) (2010) 207-212.

[26] E. M. Nielsen, J. Engberg, V. Fussing, L. Petersen, C. H. Brogren, S. L.On: Evaluation of Phenotypic and Genotypic Methods for Subtyping Campylobacter jejuni Isolates from Humans, Poultry, and Cattle. Journal of Clinical Microbiology 38(2000) 3800-3810.

[27] D. Lin, P. F. Lehmann, B. H. Hamory, A. A. Padhye, E. Durry, R. W. Pinner, B. A. Lasker: Comparison of Three Typing Methods for Clinical and Environmental Isolates of Aspergillus fumigatus. Journal of Clinical Microbiology 33(1995) 1596-1601.

[28] T. Lin, L. Lin, F. Zhang: Review on Molecular Typing Methods of Pathogens. Open Journal of Medical Microbiology 4 (2014)147-152. 